\title{
APPLICATION OF APPROACH FOR DEVELOPMENT OF HPTLC IDENTIFICATION AND QUANTIFICATION METHODS FOR DETERMINATION OF PHENOLIC COMPOUNDS AND TERPENOIDS OF SEVERAL THYMUS L. SPECIES
}

\author{
Kateryna Khokhlova, Liliia Vyshnevska, Oleksandr Zdoryk, Olga Filatova
}

The aim of this work was to improve the approaches for standardization of Thymus L. species by development of HPTLC identification of phenolic compounds (flavonoids and phenylpropanoids) and terpenoids (essential oils and triterpenoids) and quantitative determination of rosmarinic acid and flavonoids for six Thymus L. species of Ukraine flora, as well as determination of chromatographic profiles of Thymus L. species' extracts obtained using different extraction methods.

Materials and methods. Objects were: samples of dry herb of Th.serpyllum, Th.vulgaris, Th.Marschallianus, Th.Pallasianus, Th.calcareus, and Th.moldavicus of Ukraine origin collected in 2019-2021 years or acquired commercially on Ukraine market. Instruments: CAMAG HPTLC Herbal System, visionCats 2.5. The analytical grade reagents were used. Reference substances were purchased from Extrasynthese, Sigma Aldrich. Chromatography was performed on HPTLC plates Si 60 F254, Merck according to the developed methods.

Results. A new approach for quality control of different Thymus L. species of Ukraine flora included the development of HPTLC methods for identification of main groups of bioactive substances of these species, such as flavonoids and phenylpropanoids, essential oils, triterpenoids; development of quantification method of rosmarinic acid and assay of total flavonoids, expressed as luteolin-7-O-glucoside. The characteristic HPTLC fingerprints of six Thymus L. species in three mobile phases of different polarities that cover a wide range of bioactive substances were established. The content of rosmarinic acid in different Thymus L. species samples was in the range of 0,11-0,72 \%: Th.moldavicus 0,11 \%; Th.Marschallianus - 0,19-0,27 \%; Th.serpyllum - 0,38 \%; Th.vulgaris - 0,51 \%; Th.calcareus - 0,56 \%; T.Pallasianus - 0,72\%. The total flavonoids content, expressed as luteolin-7-O-glucoside, was in the range of 0,8$2,72 \%$ : Th.moldavicus - 0,8 \%; Th.serpyllum - 0,87\%; Th.vulgaris - 1,06 \%; Th.Pallasianus - 1,28 \%; Th.Marschallianus $-1,89 \%$; Th.calcareus $-2,72 \%$.

Conclusions. The proposed scientific approach for quality evaluation of Thymus L. species using HPTLC allows to determine comprehensive information of chemical composition and content of active substances of multiple samples in parallel, in a cost and time-efficient manner

Keywords: high-performance thin-layer chromatography, Thymus, standardization, identification, quantification, flavonoids, essential oils, triterpenoids

How to cite:

Khokhlova, K., Vyshnevska, L., Zdoryk, O., Filatova, O. (2021). Application of approach for development of hptlc identification and quantification methods for determination of phenolic compounds and terpenoids of several Thymus L. species. ScienceRise: Pharmaceutical Science, 4 (32), 29-36. doi: http://doi.org/10.15587/2519-4852.2021.238806

(C) The Author(s) 2021

This is an open access article under the Creative Commons CC BY license hydrate

\section{Introduction}

The Thymus L. genus belongs to the Lamiaceae family and includes several hundred species distributed in Eurasia, North Africa, Greenland [1-4]. Despite this, only a few Thymus L. species - T.vulgaris L. and T.zygis L. or its mixture, and T.serpyllum L. [5, 6] have pharmacopoeial standardization. At the same time, usually, the collectors of herbal raw material do not distinguish the species of Thymus, so its herbal raw material could be represented by different related species, as well as their combination in the various ratios $[3,4]$.

The modern high-performance thin-layer chromatography (HPTLC) method is included in the pharmacopoeial analysis [7]. It gives the possibility to compare results of different species or extraction in parallel at the same HPTLC plate or to compare tracks from different plates using "virtual plate". Moreover, the results could be stored in a traditional form of an image (chromatogram) or as peak profiles from image/densitogram. Thus, HPTLC is a useful tool for conducting not only the qualitative, but also specific and non-specific quantitative determination $[8,9]$. That enables to use of the HPTLC method for comprehensive evaluation of the quality of closely related plant species.

The aim of this work was the improvement of approaches for standardization of Thymus L. species by the development of HPTLC identification of phenolic compounds (flavonoids and phenylpropanoids) and 
terpenoids (essential oils and triterpenoids) and quantitative determination of rosmarinic acid and flavonoids of six Thymus L. species of Ukraine flora - Th.serpyllum, Th.vulgaris, Th.Marschallianus Willd., Th.Pallasianus H.Braun, Th.calcareus Klok.et Shost. and Th.moldavicus Klok.et Shost, as well as determination of chromatographic profiles of Thymus L. species' extracts, obtained using different extraction methods.

\section{Research planning (methodology)}

The design of the experiment for quality control of Thymus L. species of Ukraine flora using HPTLC included several steps: the selection and collection of objects for investigations (pharmacopoeial and non-pharmacopoeial species); determination of groups of bioactive substances/markers; determination and evaluation of existed approaches for standardization of objects if any; optimization of existed standardization approaches using comprehensive HPTLC.

A new approach for quality control of different Thymus L. species of Ukraine flora included the development of HPTLC methods for identification of main groups of bioactive substances of these species, such as flavonoids and phenylpropanoids (ID 1), essential oils (ID 2), triterpenoids (ID 3); development of quantification method of rosmarinic acid (QD RA) and a specific assay of total flavonoids, expressed as luteolin-7-O-glucoside (TFC); as well as determination of specific HPTLC fingerprints for different Thymus L. species that are important for proper authentification and discrimination of potential falsification.

\section{Materials and methods}

Objects were: samples of the dry herb of Th. vulgaris, Th. serpyllum, Th. Marschallianus, Th. Pallasianus, Th.calcareus, and Th.moldavicus of Ukraine origin collected in 2019-2021 years or acquired commercially on Ukraine market. Instruments: CAMAG HPTLC Herbal System, VisionCats 2.5. The analytical grade reagents were used. Reference substances were purchased from Extrasynthese, Sigma Aldrich. Chromatography was performed on HPTLC plates Si 60 F254 according to the developed methods.

Methods. Sample preparation for identification (ID 1 and ID 3), TFC. $100 \mathrm{mg} / \mathrm{ml}$ of powdered Thymus herb in methanol (alc. $70 \%$ or alc. $40 \%$ ), shaken for $20 \mathrm{~min}$, sonicated for $10 \mathrm{~min}$, and then centrifuged. Use the supernatant as test solution A; apply $4 \mu 1$ each. Sample preparation for identification (ID 2). Essential oils of Thymus obtained by steam distillation; $100 \mathrm{mg} / \mathrm{ml}$ of powdered Thymus herb in methanol (dichloromethane, methanol, alc. $70 \%$ or alc. $40 \%$ ), shaken for $20 \mathrm{~min}$, sonicated for $10 \mathrm{~min}$, and then centrifuged. Use the supernatant as test solution; apply $5 \mu \mathrm{l}$ each. Sample preparation for $Q D$ of $R A .3$ parts of the test solution $\mathrm{A}$ are diluted with 7 parts of methanol, to produce a second test solution at $30 \mathrm{mg} / \mathrm{ml}$; apply $4 \mu \mathrm{l}$ each. Standard preparation (ID 1, SST). $0,3 \mathrm{mg} / \mathrm{ml}$ of chlorogenic acid and $0,25 \mathrm{mg} / \mathrm{ml}$ of hyperoside in methanol (SST), apply $3 \mu \mathrm{l}$ each. $0,2 \mathrm{mg} / \mathrm{ml}$ of luteolin-7-O-glucoside and $0,4 \mathrm{mg} / \mathrm{ml}$ of rosmarinic acid in methanol (R), apply $4 \mu \mathrm{l}$ each. Standard solution $(\mathrm{R})$ is diluted with methanol one to four $\left(\mathrm{R}_{1 / 4}\right)$, apply $4 \mu \mathrm{l}$ each. Standard preparation (ID 2, SST). $0,125 \mathrm{mg} / \mathrm{ml}$ of thymol and $1,0 \mu \mathrm{l} / \mathrm{ml}$ of cineol in methanol (SST), apply $4 \mu \mathrm{l}$ each. $5 \mathrm{mg} / \mathrm{ml}$ of thymol in methanol (R), apply $4 \mu \mathrm{l}$. Standard solution (R) is diluted with methanol one to four $\left(\mathrm{R}_{1 / 4}\right)$; apply $4 \mu \mathrm{l}$. Standard preparation (ID 3, SST). $0,5 \mathrm{mg} / \mathrm{ml}$ of ursolic acid and $2 \mathrm{mg} / \mathrm{ml}$ of borneol in methanol (SST), apply $4 \mu \mathrm{l}$ each. $0,5 \mathrm{mg} / \mathrm{ml}$ of oleanolic acid (R), apply $4 \mu \mathrm{l}$; standard solution $(R)$ is diluted with methanol one to four $\left(R_{1 / 4}\right)$, apply $4 \mu 1$. Optional. $1 \mathrm{mg} / \mathrm{ml}$ of $\beta$-sitosterin in methanol, apply $3 \mu 1$. Standard preparation ( $Q D$ of $R A$ ). 5 calibration solutions in a range of $0,2-1,0 \mu \mathrm{g} /$ zone of rosmarinic acid in methanol. Standard preparation (TFC). 5 calibration solutions in a range of $0,2-0,8 \mu \mathrm{g} /$ zone of luteolin-7O-glucoside in methanol. Stationary phase (Type, size). HPTLC Si 60 F254 (Merck), 20x20. Mobile phase (ID 1, QD RA). Ethyl acetate, formic acid anhydrous, water (8:1:1). Mobile phase (ID 2). Dichloromethane. Mobile phase (ID 3). Toluene-ethylacetate-formic acid (7:3:0,1). Mobile phase (TFC). Ethyl acetate, formic acid anhydrous, water (8:1:1). Saturation. 20 min (with saturation pad). Humidity control. $10 \mathrm{~min}$ with $\mathrm{MgCl} 2$ (33\% relative humidity). Developing distance. $62 \mathrm{~mm}(70 \mathrm{~mm}$ from the lower edge). Derivatization (ID 1). Name: NP/PEG. Preparation: NP: $5 \mathrm{mg} / \mathrm{ml}$ of 2-aminoethyl diphenylborinate in ethyl acetate. PEG: $50 \mathrm{mg} / \mathrm{ml}$ of polyethylene glycol 400 in dichloromethane. Use: preheat the plate at $100{ }^{\circ} \mathrm{C}$ for $3 \mathrm{~min}$. Dip the warm plate into NP and then in PEG (dipping speed: 5, dipping time: 0). Derivatization (ID 2, ID 3). Name: Anisaldehyde-sulfuric acid reagent. Preparation: $10 \mathrm{ml}$ sulphuric acid is carefully added to an ice-cooled mixture of $170 \mathrm{ml}$ methanol and $20 \mathrm{ml}$ acetic acid. To this solution, $1 \mathrm{ml}$ anisaldehyde is added. Use: dip the plate into reagent (speed: 5, time: 0); heat the plate at $100{ }^{\circ} \mathrm{C}$ for $3 \mathrm{~min}$. Derivatization (TFC). Name: Aluminium chloride. Preparation: $5 \mathrm{~g}$ aluminium chloride is dissolved in $100 \mathrm{ml}$ $70 \%$ alcohol. Use: dip the plate into reagent (speed: 5 , time: 0). Detection (ID 1, ID 2, ID 3). Record images in white light, UV $254 \mathrm{~nm}$, UV $366 \mathrm{~nm}$ before derivatization; and white light, UV $366 \mathrm{~nm}$ after derivatization. Densitometry ( $Q D \quad R A)$. Record densitogram in UV $330 \mathrm{~nm}$ before derivatization with TLC Scanner, absorbance mode, slit dimension 5,0 x 0,2 mm, scanning speed $20 \mathrm{~mm} / \mathrm{s}$, spectra recording from 190 to $450 \mathrm{~nm}$. Detection (TFC). Record images in UV $366 \mathrm{~nm}$ after derivatization. Densitometry (TFC). Record densitogram in UV $400 \mathrm{~nm}$ before and after derivatization with TLC Scanner, absorbance mode, slit dimension $5.0 \times 0.2 \mathrm{~mm}$, scanning speed $20 \mathrm{~mm} / \mathrm{s}$, spectra recording from 190 to $550 \mathrm{~nm}$.

\section{Results}

Two pharmacopoeial Thymus L. species (Th. vulgaris and Th. serpyllum) and four nonpharmacopoeial species of Ukraine flora that have collection resources (Th. Marschallianus, Th. Pallasianus, Th. calcareus, and Th. moldavicus) [1, 2, 4, 6] were selected for investigation. According to literature data, the main bioactive substances of Thymus L. species are phenolic compounds, essential oils, and triterpenoids [2].

For standardization of Thymus L. species different approaches exist. The SPhU and European Pharmacopoeia monographs for Thymus, describing 2 species $-T$. vulgaris and $T$. zygis or its mixture, include TLC/HPTLC 
method for flavonoids and phenylpropanoids (markers used are rutin and rosmarinic acid) identification and essential oils content determination (steam distillation (SD) and gas chromatography (GC), while monograph for T.serpyllum quality assessment requires: the identification of essential oils by TLC (markers are thymol and carvacrol), its content by SD method, determination of extractable matters. Thus, the approaches for TLC/HPTLC identification used $[5,6]$ require the determination of different groups of bioactive substances for related Thymus species, neither consider related non-pharmacopoeial Thymus species of Ukraine flora, nor allow to distinguish them between each other or to show their similarity. Besides, the control of temperature and relative humidity that are necessary for reproducible HPTLC analysis, SST, intensity markers are not required; evaluation of results is performed according to the reference table, which is often difficult for interpretation. The approach for quantification of Thymus and T.serpyllum [5, 6] includes determination of the content of essential oils by SD (2.8.12), which is cumbersome and unspecific assay method; besides, a monograph on Thymus requires determination of essential oils (sum of thymol and carvacrol) by GC method, that despite the specificity requires time-consuming sample preparation; a monograph on T.serpyllum requires determination of extractable matters, extracted with $30 \%$ alcohol (non-specific assay). Another pharmacopoeial approach for standardization of T.serpyllum [10] includes TLC identification of flavonoids (specific marker luteolin7-O-glycoside is used) and spectrophotometry assay of TFC, after complexation reaction with aluminium chloride, expressed as luteolin-7-O-glycoside; determination of extractable matters, extracted with $30 \%$ alcohol and water (non-specific assay). Besides, for T.serpyllum different spectrophotometry assay methods of TFC, expressed as rutin [11], and total content of hydroxycinnamic acids, expressed as rosmarinic acid [3] were published.
The optimization of existed standardization approaches using HPTLC. Several HPTLC methods for identification of main groups of compounds (flavonoids and phenylpropanoids; essential oils, triterpenoids) of T.vulgaris, T.serpyllum, T.Marschallianus, T.Pallasianus, Th.calcareus, and Th.moldavicus were developed.

The identification of flavonoids and phenylpropanoids was performed in the mobile phase: ethyl acetate, water, formic acid anh. (8:1:1). For system suitability test (SST) such pairs of substances were tested: hyperoside (1) and chlorogenic acid (2); quercetin (3) and rosmarinic acid (4); luteolin (5) and rosmarinic acid (4); luteolin (5) and caffeic acid (6), hyperosode (1) and quercetin-3-glucoside (8), hyperoside (1) and luteolin-7-O-glucoside (10) (Fig. 1, A). The suitable SST pairs in this MP were $(1,2) ;(3,4) ;(1,8)$, and $(1,10)$. These pairs had close $R_{F}$ values, but were clearly separated. For the selection of reference substances and intensity markers, chemotaxonomic markers of Thymus, such as rosmarinic acid (4) and luteolin-7-O-glucoside (10), as well as other phenolic compounds were tested (Fig. 1,a). The most specific combinations of markers for usage as a reference solution and intensity markers for flavonoids' and phenylpropanoids' identification of Thymus L. species are luteolin-7-O-glucoside and rosmarinic acid. The extraction method (sonication) gave less consistent results than extraction with automated shaking; extraction with combined technique (20 min of shaking and $10 \mathrm{~min}$ of sonication) gave more intense zones of fingerprints and was chosen for further analysis (Fig. 1, b).

Comparison of HPTLC fingerprints of methanolic and $70 \%$ and $40 \%$ alcoholic extracts showed their similarity, despite differences in chlorophylls appearance close to the front position (Fig. 1, b). This is important for the transfer of the method for the finished herbal drugs of Thymus L. species.
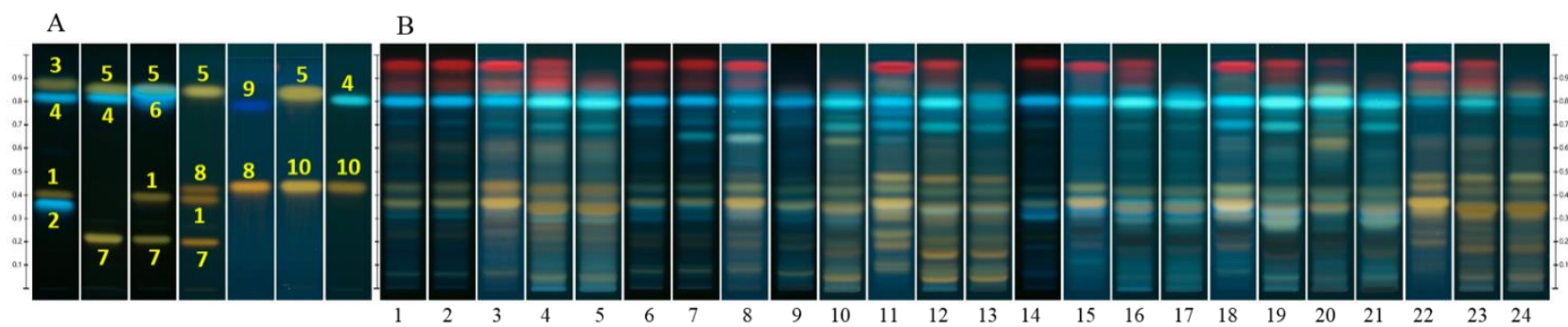

Fig. 1. Identification of flavonoids and phenylpropanids. Selection of SST, intensity markers, solvents and extraction technique: A - Reference standards for SST and intensity markers: 1 - hyperoside; 2 - chorogenic acid; 3 - quercetin; 4 - rosmarinic acid; 5 - luteolin; 6 - caffeic acid; 7 - rutin; 8 - quercetin-3-glucoside; 9 - gallic acid; 10 - luteolin-7-Oglycoside; B - Tracks: 1-5 - Th.vulgaris: 1 - son., meth.; 2 - shak., meth.; 3 - shak+son., meth.;

4 - shak+son., $70 \%$ alc.; 5 - shak+son., $40 \%$ alc.; 6-10 - Th.serpyllum: 6 - son., meth.; 7 - shak., meth.;

8 - shak+son., meth.; 9 - son., $70 \%$ alc.; 10 - shak+son., $40 \%$ alc.; 11-13 - Th.Marshallianus: 11 - shak+son., meth.; 12 - shak+son., $70 \%$ alc.; 13 - shak+son., $40 \%$ alc; $14-17$ - Th.Pallasianus: 14 - shak.,meth.; 15 - shak+son. Meth.; 16 - shak+son., $70 \%$ alc.; 17 - shak+son., $40 \%$ alc; $18-21-$ Th.calcareus: 18 - shak+son. meth.;

19 - shak+son., $70 \%$ alc.; 20 - ac. hydr., $70 \%$ alc.; 21 - shak+son., $40 \%$ alc.;

22-24 - Th.moldavicus: 22 - shak+son., meth.; 23 - shak+son., $70 \%$ alc.; 24 - shak+son., $40 \%$ alc.

According to the results of identification obtained in different detection modes (Fig. 2), five Thymus L. species had a pair of orange (red arrows) and yellowgreen (green arrows) zones due to flavonoids in the middle part of the chromatogram, while the analyzed sample of Th.vulgaris had a slight difference in flavonoids fingerprints and showed a pair of orange zones in the middle part of the chromatogram (red and yellow arrows) and characteristic diffuse yellow zone in the upper third (orange arrow); all Thymus species had rosmarinic acid 
in the upper part of chromatogram (white arrows). At $366 \mathrm{~nm}$ at the middle part of the chromatogram,
Th.Pallasianus and Th.calcareus showed more light-blue zones due to phenylpropanoids.
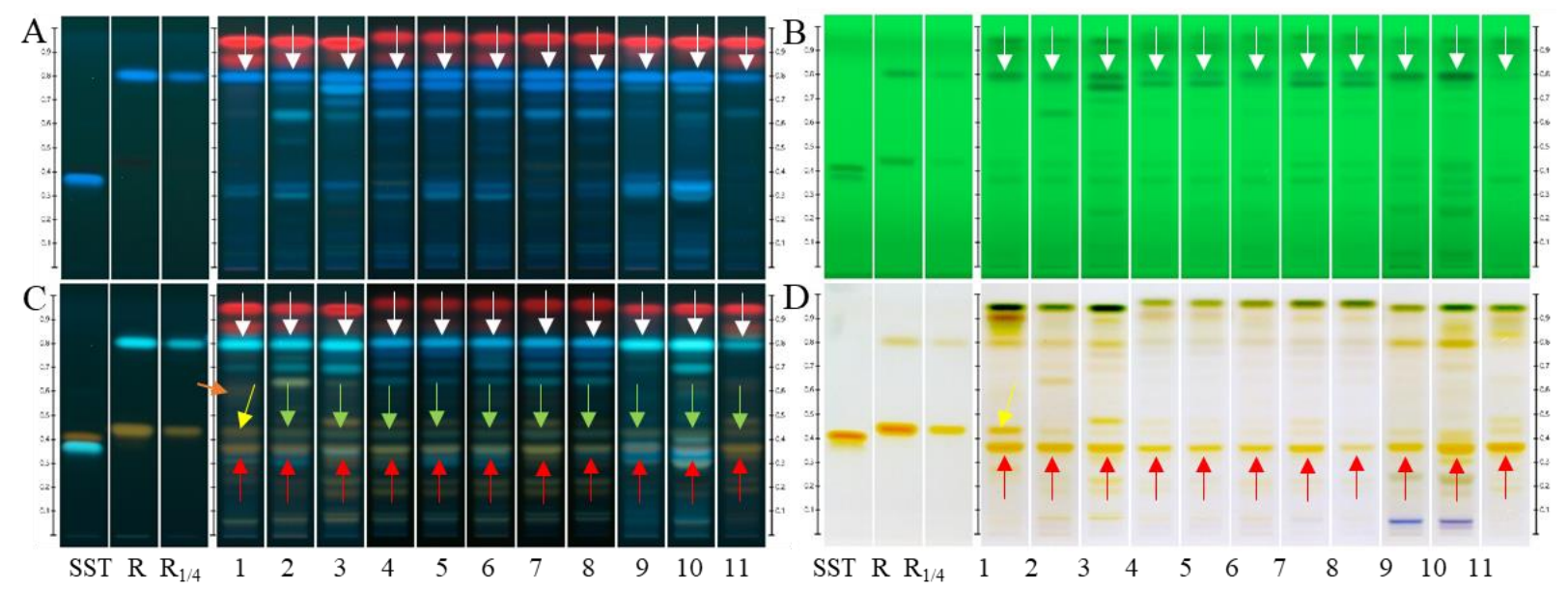

Fig. 2. Identification of flavonoids and phenylpropanoids. Different detection modes: A - 366 nm before derivatization; $\mathrm{B}-254 \mathrm{~nm}$ before derivatization; $\mathrm{C}-366 \mathrm{~nm}$ after derivatization; D - WRT after derivatization. SST: chlorogenic acid, hyperoside $\left(R_{F} \uparrow\right)$; R - luteolin-7-O-glycoside, rosmarinic acid; R1/4 - luteolin-7-O-glycoside, rosmarinic acid.

Tracks: 1 - Th.vulgaris, 2 - Th.serpyllum, 3-8-Th. Marschallianus; 9 - Th. Pallasianus; 10 - Th.calcareus; 11 - Th.moldavicus; meth.

The identification of essential oils was performed in mobile phase: dichloromethane, where orange zone due to thymol was in the middle part of chromatogram with $R_{F} \approx 0,44$ (Fig. 3, a). Cineol and thymol could be proposed for SST; thymol can be used as a reference solution and intensity marker (Fig. 3). Comparison of chromatographic fingerprints of samples with different extraction techniques and solvents (dichlormethane (DCM), methanolic, $70 \%$ alcoholic and $40 \%$ alcoholic extracts obtained by automated shaking and essential oils obtained by SD) showed differences in their content and composition, with more intense essential oils' zones in samples of essential oil obtained by SD (Fig. 3). Essential oils of Thymus L. species obtained by SD showed the presence of zone due to thymol (green arrows) in Th.vulgaris, Th.serpyllum, Th.Marschallianus and Th.moldavicus; the Th.Pallasianus and Th.calcareus samples did not show the zone due to thymol. Thymol was found to be the main essential oil in methanolic and alcoholic extracts of T.vulgaris, T.serpyllum, T.Marschallianus, while T.Pallasianus and Th.calcareus, which are xerophyte plants, did not show the zone due to thymol either or showed its low content (Th.moldavicus). Th.calcareus essential oil and extracts showed a violet zone of different intensity that was positioned slightly below the zone due to thymol (red arrows). The violet zone of different intensity $\left(R_{F} \approx 0,22\right.$, violet arrows) was present in essential oils of all Thymus $L$. species besides Th.serpyllum; and was of light intensity in their methanolic extracts. The violet zone with $R_{F} \approx 0,22$ might be probably due to caryophyllene oxide, but this assumption requires confirmation with reference substance and its UV/MS comparison. The brownish zone with $R_{F} \approx 0,16$ (probably, due to borneol) was present in all Thymus L. species' samples obtained by SD and was not detected in their methanolic/alcoholic extracts.

Along with flavonoids, phenylpropanoids, and essential oils, triterpenoids are an important group of bioactive substances of the Thymus [3, 12]. Triterpenoids can strongly influence the biological activity of plants [13]. For example, oleanolic acid which is a pentacyclic triterpenoid has antitumor, antidiabetic, antimicrobial, hepatoprotective, antihypertensive, antioxidant, anti-inflammatory, antiparasitic activities [12-14]. Despite this, triterpenoids are not used for pharmacopoeial standardization of Thymus L. species.

The developed HPTLC identification of triterpenoids was performed in the mobile phase: tolueneethylacetate-formic acid (7:3:0,1). In this mobile phase, it was possible to detect both triterpenoid oleanolic acid and essential oil thymol. For SST ursolic acid and essential oil borneol can be used. As a reference solution and intensity markers oleanolic acid and thymol can be proposed.

As we can see in Fig. 4, oleanolic acid was present in methanolic and $70 \%$ alcoholic extracts of all Thymus L. species (violet arrows), and absent in $40 \%$ alcoholic extracts. 


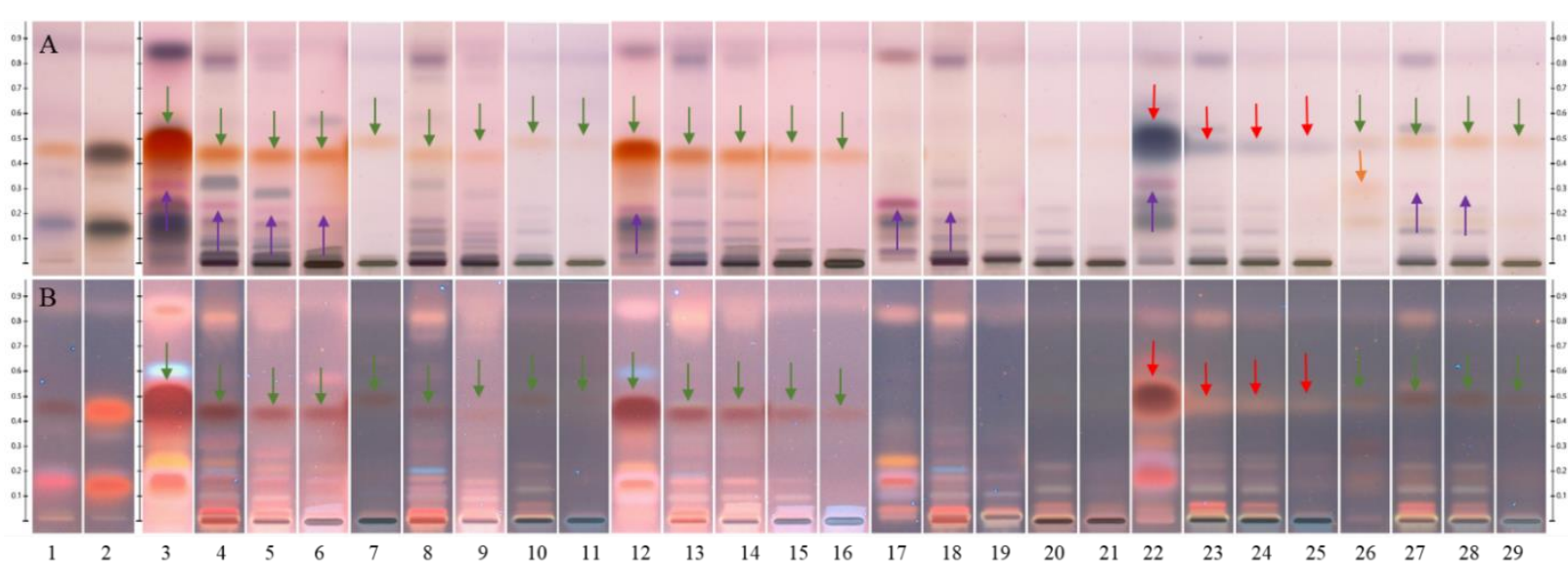

Fig. 3. Identification of essential oils. Selection of SST, intensity markers, comparison of solvents and extraction techniques: A - WRT after derivatization; B - $366 \mathrm{~nm}$ after derivatization. Tracks: 1 - menthol, cineol, thymol, RF $\uparrow$;

2 - borneol, bornyl acetate; 3-7 - Th.vulgaris: 3 - essential oil; 4 - DCM; 5 - meth.; 6 - $70 \%$ alc.; 7 - $40 \%$ alc.; 8-11 - Th.serpyllum: 8 - DCM; 9 - meth.; $10-70 \%$ alc.; $11-40 \%$ alc.; 12-16 - Th. Marschallianus: 12 - essential oil; 13 - DCM; 14 - meth., $15-70 \%$ alc.; $16-40 \%$ alc.; 17-21 - Th. Pallasianus: 17 - essential oil; 18 - DCM;

19 - meth.; $20-70 \%$ alc.; $21-40 \%$ alc.; 22-25 - Th. calcareus: 22 - essential oil; 23 - meth., $24-70 \%$ alc.; $25-40 \%$ alc.; 26-29 - Th.moldavicus: 26 - essential oil; 27 - meth., 28 - $70 \%$ alc.; 29 - $40 \%$ alc.

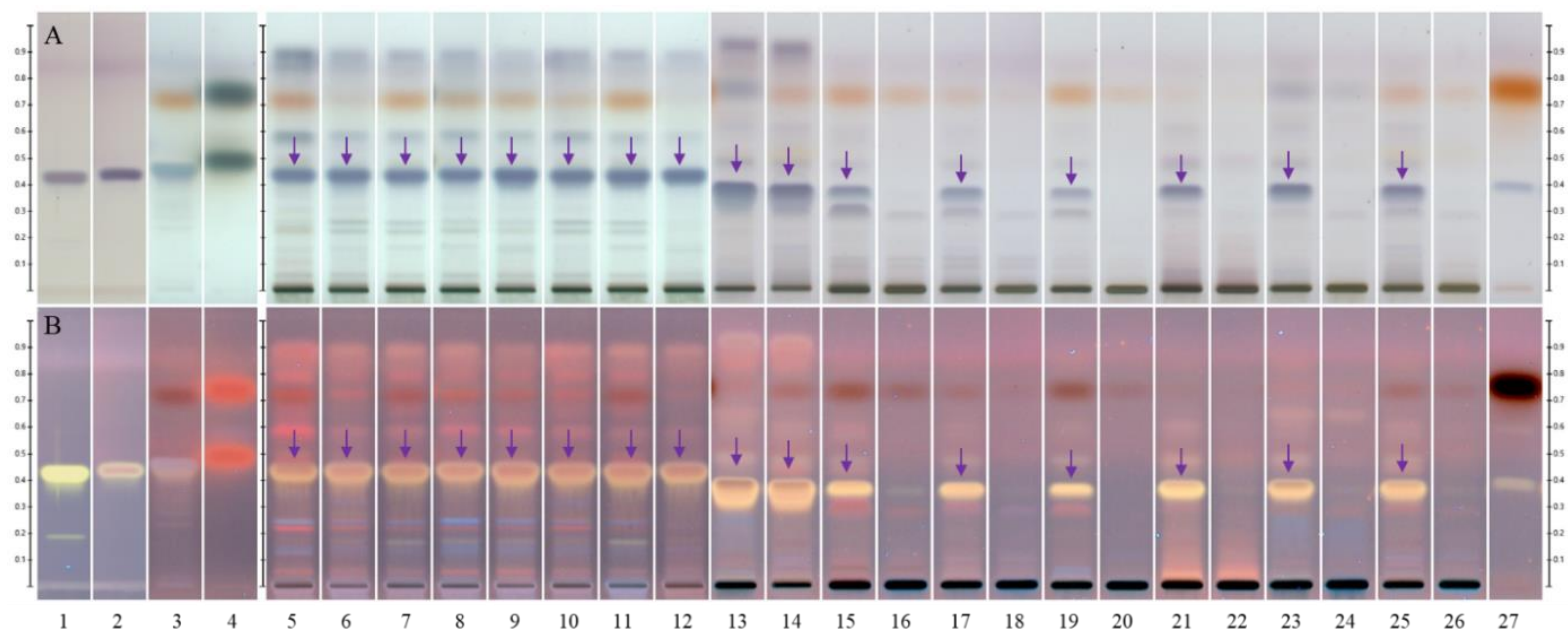

Fig. 4. Identification of triterpenoids. Different detection modes: A - WRT after derivatization; B - $366 \mathrm{~nm}$ after derivatization. Tracks: 1 - ursolic acid; 2 - oleanolic acid; 3 - B-sitosterin, thymol, $\mathrm{R}_{\mathrm{F}} \uparrow ; 4$ - borneol, bornyl acetate $\mathrm{R}_{\mathrm{F}} \uparrow$; 5 - Th.vulgaris, meth.; 6 - Th.serpyllum, meth.; 7-11 - Th. Marschallianus, meth.; 12 - Th. Pallasianus, meth.; 13 - Th. calcareus, meth.; 14 - Th. moldavicus. meth.; 15 - Th.vulgaris, $70 \%$ alc.; 16 - Th.vulgaris, $40 \%$ alc.; 17 - Th. serpyllum, $70 \%$ alc.; 18 - Th. serpyllum, $40 \%$ alc.; 19 - Th. Marshallianus, $70 \%$ alc.; 20 - Th. serpyllum, $40 \%$ alc.; $21-$ Th. Pallasianus, $70 \%$ alc.; $22-$ Th. Pallasianus, $40 \%$ alc.; $23-$ Th. calcareus, $70 \%$ alc.; 24 - Th. calcareus, $40 \%$ alc.; 25 - Th. moldavicus, $70 \%$ alc.; 26 - Th. moldavicus, $40 \%$ alc.; 27 - oleanolic acid, thymol, $\mathrm{R}_{\mathrm{F}} \uparrow$

For quantitative determination of Thymus, the HPTLC methods for specific determination of phenylpropanoid - rosmarinic acid, as well as TFC, expressed as luteolin-7-O-glycoside, were proposed.

Rosmarinic acid was present in all investigated Thymus L. species and according to the literature is responsible for antioxidant, anti-inflammatory, antiviral, anti-allergy activities [15], thus, it can be considered as an active marker. With the same mobile phase used for ID 1, the quantification of rosmarinic acid was performed at $330 \mathrm{~nm}$ by peak profile from scanning densitometry (PPSD). The detection mode at $330 \mathrm{~nm}$ was chosen as it corresponded to the maximum of rosmarinic acid. The specificity of the quantification method was proved by the comparison of $R_{F}$ of zones due to rosmarinic acid reference standard and Thymus L. species samples, as well as by the comparison of their UV spectrum (Fig. 5). The calculations were done using CAMAG visionCATs software. The validation parameters of the method such as linearity (calibration function: $y=0,0077 x+0,0015$, correlation coefficient $(\mathrm{R})=0,9998, \quad \mathrm{LOD}=0,0218$ ( $\mu \mathrm{g} / \mathrm{band}), \mathrm{LOQ}=0,0662 \quad(\mu \mathrm{g} / \mathrm{b}$ and $)$, precision $(\mathrm{n}=6$, $\mathrm{RSD}=0,1 \%)$, repeatability $(\mathrm{n}=3, \mathrm{RSD}=0,9 \%)$, accuracy $(95,9 \%)$ were determined. According to the results the content of rosmarinic acid in different Thymus L. species samples, calculated on the dry raw material, was in the range of $0,11-0,72 \%$ : Th.moldavicus - 0,11 \%; Th.Marschallianus - 0,19-0,27 \%; Th.serpyllum - 0,38\%; Th.vulgaris - 0,51\%; Th.calcareus - 0,56\%; T.Pallasianus $-0,72 \%$. 
A

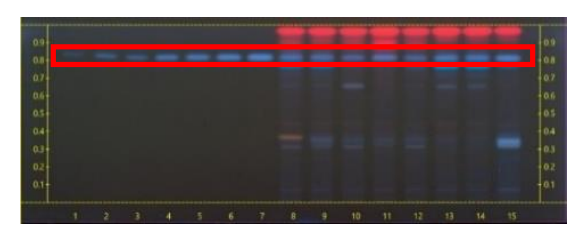

B

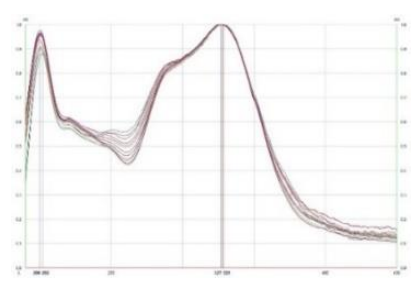

$\mathrm{C}$

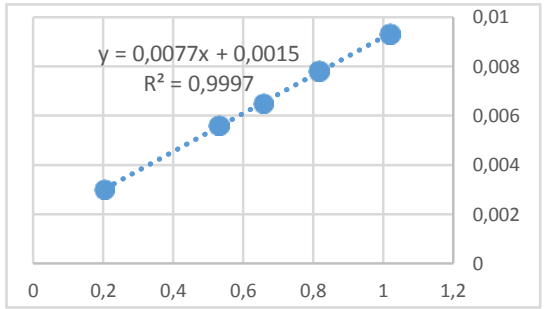

Fig. 5 Quantitative determiantion of rosmarinic acid in Thymus L. spp. samples: A - Chromatogram of rosmarinic acid and Thymus L. species samples; B - Spectrum comparison of rosmarinic acid and zones due to rosmarinic acid; $\mathrm{C}$ - Calibration curve for rosmarinic acid at $330 \mathrm{~nm}$ (scanner)

Total flavonoids are responsible for antioxidant, anti-inflammatory, antimicrobial, hepatoprotective, antiviral activities of the plant [11]. The assay method for TFC, expressed as luteolin-7-O-glycoside, calculated on a dry basis, was developed. The separation of bioactive substances was performed in the mobile phase: ethyl acetate, formic acid anhydrous, water (8:1:1), then the plate was dipped in aluminum chloride reagent, and detected after 2 hours at $400 \mathrm{~nm}$ by scanning densitometry, subtracting peaks at $400 \mathrm{~nm}$ before derivatization (Fig. 6). The areas of all peaks of the flavonoids profile of the sample were measured and added. The expression was done using the standard substance luteolin-7-O-glycoside that was applied onto the same plate as sample solutions. The comparison of TFC of methanolic extracts of different Thymus L. species was done by the method (Fig. 6, 7). According to the results, the TFC was in the range of 0,8-2,72 \%: Th.moldavicus $-0,8 \%$; Th.serpyllum - 0,87 $\%$; Th.vulgaris - 1,06 \%; Th.Pallasianus - 1,28\%; Th.Marschallianus $-1,89 \%$; Th.calcareus $-2,72 \%$.

The comparison of the quantity of rosmarinic acid and total flavonoids of different Thymus L. species is shown in Fig. 7.

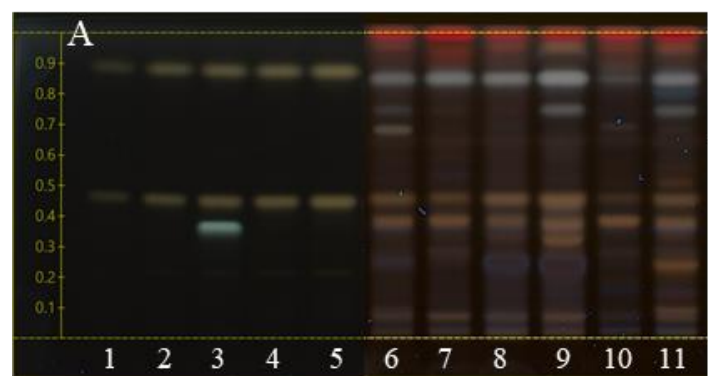

B

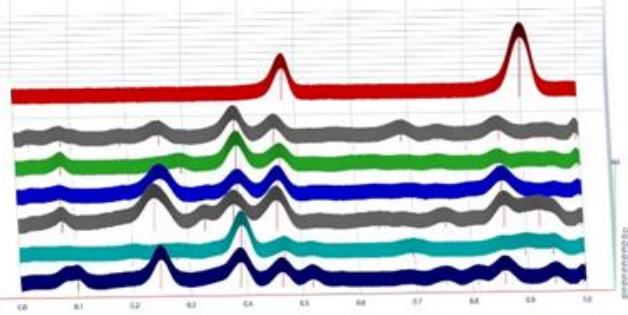

Fig. 6. Determination of TFC, expressed as luteolin-7-O-glucoside, in methanolic extracts of Thymus L. species. A. Image, $366 \mathrm{~nm}$ after derivatization. B. densitogram, $400 \mathrm{~nm}$ after derivatization. Tracks: 1-5 - luteolin-7-O-glucoside, luteolin; 3 - chlorogenic acid (blue zone); 6 - Th.serpyllum 7 -Th.vulgaris, 8 - Th. Pallasianus; 9 - Th. calcareus; 10 - Th. moldavicus; 11 - Th. Marschallianus; meth.

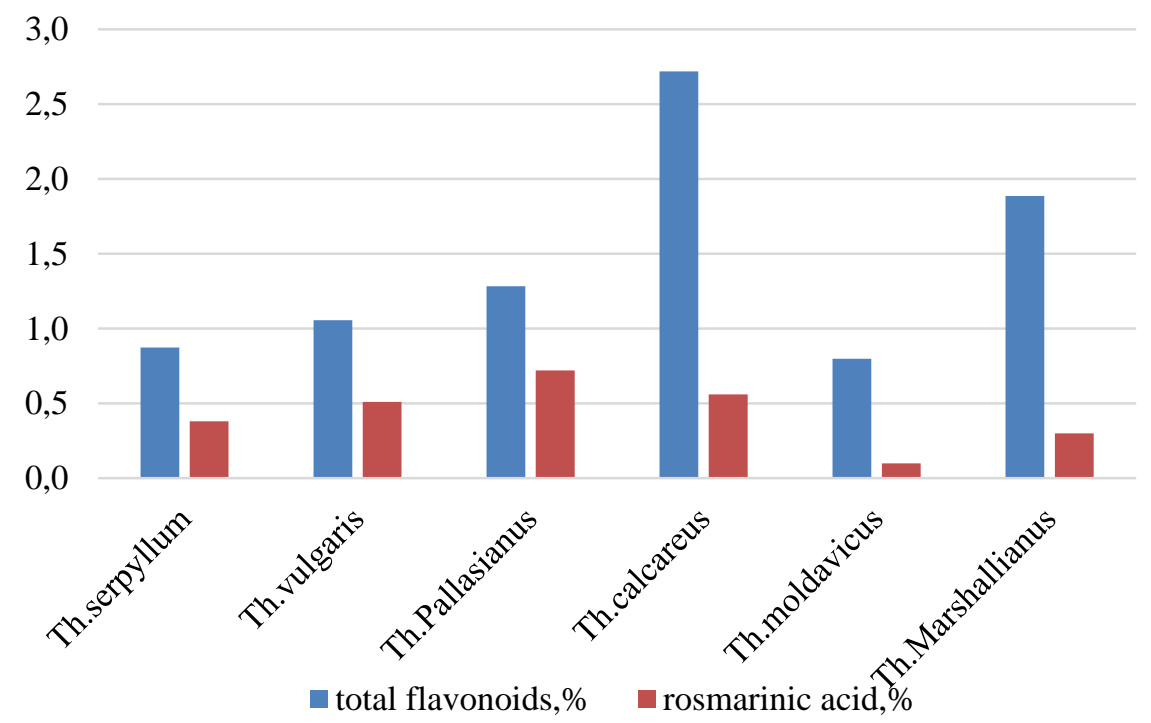

Fig. 7. Comparison of content of rosmarinic acid and total flavonoids in different Thymus L. species 
As we can see from Fig. 7, Th. calcareus and Th. Marshallianus methanolic extracts showed the most content of flavonoids, while Th. Pallasianus and Th. calcareus shown greater content of rosmarinic acid.

\section{Discussion}

The proposed scientific approach for quality evaluation of Thymus L. species using HPTLC allows to determining the comprehensive information of chemical composition and content of active substances of multiple samples of various species, obtained by a different technology, in parallel, in a time and cost-efficient manner. The findings obtained using developed HPTLC methods, prove the presence of main groups of substances: flavonoids, phenylpropanoids, essential oils, and triterpenoids in all Thymus L. species [3]; show the influence of solvent and extraction technique for its composition; provide similarity and differences in HPTLC fingerprints of different Thymus L. species, that growth on different soils (Fig. 1-7). For example, the comparison of essential oils fingerprints of Thymus L. species showed the presence of thymol as the main component in Th. serpyllum, Th. vulgaris and Th. Marshallianus and different essential oils composition with no or low content thymol found in three investigated Thymus L. species that grow in dry and poor soils Th.Pallasianus (sands), Th.calcareus (chalk mountains), and Th.moldavicus (shelly soil).

The results prove the replacing of TLC on essential oils by HPTLC using flavonoids profile by European pharmacopoeia for distinguishing of both pharmacopoeial species - Th.serpyllumand Th.vulgaris that have similar essential oils composition (thymol chemotype) (Fig. 3) [16]; confirm the possibility of standardization of Thymus L. species by flavonoids and hydroxycinnamic acids (rosmarinic acid) content (Fig. 1, 2) [3]; and show the prospect of inclusion of Th. Marshallianus, which is the most widespread Ukraine species, into pharmacopoeial analysis, based on similarity of HPTLC fingerprints of main bioactive substances with Th.serpyllum.

Study limitations. The limitations of the approach are a necessity of usage of sophisticated equipment, cost of consumables.

Prospects for further research. The collection and evaluation of new Thymus L. species samples from different years and origins using proposed comprehensive HPTLC, and verification of results in different labs are of major importance.

\section{Conclusions}

The scientific approach for quality evaluation of six Thymus L. species using comprehensive HPTLC, with HPTLC methods that were respectfully developed, allowing determining: flavonoids, phenylpropanoids, essential oils and triterpenoids, and content of active substances: rosmarinic acid and flavonoids, of multiple samples in parallel, in a cost and time-efficient manner was proposed.

The similarity and differences in HPTLC fingerprints of different Thymus L. species that grow on different soils were shown. The findings are important for the selection of the place of growth of Thymus L. species during of implementation of GACP in Ukraine.

The prospect of inclusion of Th. Marshallianus, which is a mostly widespread Thymus L. species in Ukraine, into pharmacopoeial analysis, based on similarity of HPTLC fingerprints and content of its main bioactive groups of substances with Th. serpyllum was highlighted.

\section{Conflict of interests} interests.

The authors declare that they have no conflicts of

Financing. The study was performed without financial support.

\section{References}

1. Dobrochaeva, D. N., Kotov, M. I., Prokudin, Iu. N. et. al. (1987). Opredelitel vysshikh rastenii Ukrainy. Kyiv: Naukova dumka, 548.

2. Shishkin, B. K. (Ed.) (1954). Flora SSSR. Vol. XXI. Moscow: AN SSSR, 704.

3. Starchak, Iu. A. (2016). Farmakognosticheskoe izuchenie rastenii roda timian (Thymus L.) kak perspektivnogo istochnika polucheniia fitopreparatov. Kursk, 472 .

4. Ivashin, D. S., Katina, Z. F., Rybachuk, I. Z., Ivanov, V. S., Butenko, L. T. (1974). Lekarstvennye rasteniia Ukrainy. Spravochnik dlia sborschika i zagotovitelia. Kyiv: Urozhai, 360.

5. European Pharmacopoeia 9.0. (2016). Available at: https://www.coe.int/en/web/portal/-/the-9th-edition-europeanpharmacopoeia-maintaining-high-quality-standards-in-a-dynamic-global-environment

6. Derzhavna farmakopeia Ukrainy (2.0). (2015). Kharkiv: DP «Naukovo-ekspertnyi farmakopeinyi tsentr.

7. Derzhavna farmakopeia Ukrainy Dop. 2 (2nd ed.). (2018). Kharkiv: DP «Naukovo-ekspertnyi farmakopeinyi tsentr.

8. Cacigueral, S., Frommenwiler, D., Reich, E., Roser, V. (2018). High performance thin-layer chromatography (HPTLC) in the quality control of herbal products. Recent Advances in Pharmaceutical Sciences VIII, 119-136.

9. Do, T. K. T., Clark, K., Christen, P., Reich, E. (2020). Quality assessment of Sclerocarya birrea leaves and leaves products from Burkina Faso based on fingerprinting using HPTLC. JPC - Journal of Planar Chromatography - Modern TLC, 33 (5), $439-448$. doi: http://doi.org/10.1007/s00764-020-00058-5

10. Russia State Pharmacopoeia 13 (XIII) online. Available at: https://pharmacopoeia.ru/en/gosudarstvennaya-farmakopeyaxiii-online-gf-13-online/

11. Marakhova, A. I. (2016). Unifikatsiia fiziko-khimicheskikh metodov analiza lekarstvennogo rastitelnogo syria i kompleksnykh preparatov na rastitelnoi osnove. Moscow, 313.

12. Nowak, R., Wójciak-Kosior, M., Sowa, I., Sokołowska-Krzaczek, A., Pietrzak, W., Szczodra, A., Kocjan, R. (2013). HPTLC-densitometry determination of triterpenic acids in Origanum vulgare, Rosmarinus officinalis and Syzygium aromaticum. Acta poloniae pharmaceutica, 70 (3), 413-418. 
13. Ayeleso, T., Matumba, M., Mukwevho, E. (2017). Oleanolic Acid and Its Derivatives: Biological Activities and Therapeutic Potential in Chronic Diseases. Molecules, 22 (11), 1915. doi: http://doi.org/10.3390/molecules22111915

14. A pipeline for the discovery, sustainable production and commercial utilisation of known and novel high-value triterpenes with new or superior biological activities (2018). Available at: https://cordis.europa.eu/project/id/613692/reporting

15. Khokhlova, K. O., Vyshnevska, L. I., Zdoryk, O. A., Kapustianskyi, I. Yu. (2021). Pat. No. 146608 UA. Sposib kilkisnoho vyznachennia kysloty rozmarynovoi metodom vysokoefektyvnoi tonkosharovoi khromatohrafii. MPK: G01N 33/02 (2006.01). No. u202006908; declareted: 28.10.2020; published: 04.03.2021, Bul. No. 9.

16. Pharmeuropa Archives (2012). Texts for comment 24.4. EDQM. Available at: https://pharmeuropa.edqm.eu/app/Archives/ content/Archives-37164/Pharmeuropa_24.04E.pdf

Received date 12.06.2021

Accepted date 05.08.2021

Published date 31.08.2021

Kateryna Khokhlova*, PhD, Associate Professor, Department of Technology of Drugs, National University of Pharmacy, Pushkinska str., 53, Kharkiv, Ukraine, 61002

Liliia Vyshnevska, Doctor of Pharmaceutical Sciences, Professor, Department of Technology of Drugs, National University of Pharmacy, Pushkinska str., 53, Kharkiv, Ukraine, 61002

Oleksandr Zdoryk, Doctor of Pharmaceutical Sciences, Professor, Department of Quality, Standardization and Certification of Drugs, Institute of Professional Skills Improvement in Field of Pharmacy, National University of Pharmacy, Pushkinska str., 53, Kharkiv, Ukraine, 61002

Olga Filatova, PhD, Associate Professor, Department of Botany, National University of Pharmacy, Pushkinska str., 53, Kharkiv, Ukraine, 61002

*Corresponding author: Kateryna Khokhlova, e-mail: kateryna_khokhlova@ukr.net 